\title{
Facile One-pot Synthesis of Silver Nanoparticles Supported on a-Zirconium Phosphate Single-Layer Nanosheets
}

\author{
Jingfang $\mathrm{Yu}^{1,2}$ and Luyi Sun $^{1 *}$
}

In this paper, we report a facile one-pot synthesis method to prepare well dispersed silver nanoparticles (NPs) supported on $\alpha$-zirconium phosphate $(\alpha-\mathrm{ZrP})$ single-layer nanosheets. Silver NPs with a narrow size distribution were reduced on $\alpha-Z r P$ single-layer nanosheet surface due to the electrostatic attractions between the positively charged silver cations and the negatively charged $\alpha$-ZrP nanosheet support. Three reducing agents: glucose, $\mathrm{NaBH}_{4}$, and tri-sodium citrate were used to reduce $\mathrm{Ag}^{+}$. Transmission electron micrographs show that the reduced silver NPs were well dispersed with a diameter of $18.3 \pm 4.4 \mathrm{~nm}, 48.9 \pm 13.8 \mathrm{~nm}$, and $3.5 \pm 1.0 \mathrm{~nm}$ when reduced by glucose, $\mathrm{NaBH}_{4}$, and trisodium citrate, respectively. Overall, we present a facile method to synthesize Ag NPs with various dimensions for widespread applications.

Keywords: Silver nanoparticle; Single-layer nanosheets; $\alpha$-Zirconium phosphate

Received 29 March 2019, Accepted 18 May 2019

DOI: $10.30919 /$ esmm5f 223

\section{Introduction}

Metal nanoparticles (NPs) have been extensively studied because of their novel properties different from their bulky counterparts. ${ }^{1}$ Previous studies have been focusing on controlling the morphology and size of NPs, which have led to tunable properties and promising applications in electronics, ${ }^{2}$ optics, ${ }^{3}$ magnetics, ${ }^{4}$ and catalysis. ${ }^{5}$ Studies on Ag NPs are of particular interest in recent years thanks to their excellent optical properties, ${ }^{6}$ antibacterial effect, ${ }^{7}$ and catalytic performance. ${ }^{8}$ Different methods on controlling the size of Ag NPs have been developed. However, a facile and efficient method to prepare well dispersed $\mathrm{Ag}$ NPs with a proper range of size distribution is desired.

One of the characteristic properties of Ag NPs is their optical properties. Usually, highly dispersed metal NP suspensions are intense in color. The optical properties of metal NPs are the result of collective oscillations of conduction electrons of the metal, which is termed as surface plasmon polariton resonance $(\mathrm{SPPR})^{6}$ when excited by electromagnetic radiation. Among all metals, silver has the most intensive surface plasmon resonance (SPR) band. Moreover, silver maintains the highest extinction ratio in the SPR band peak among all known materials that absorb in the same spectrum range. ${ }^{7}$ Another characteristic property of silver NPs is their antibacterial effect, which is probably because microorganisms are incapable of developing mutations that can resist silver. ${ }^{9}$ A small amount of silver NPs can kill most types of bacteria ${ }^{10}$ and they can potentially act as antiviral agents, ${ }^{11}$

${ }^{1}$ Polymer Program, Institute of Materials Science and Department of Chemical \& Biomolecular Engineering, University of Connecticut, Storrs, Connecticut 06269, USA

${ }^{2}$ Chemistry Research Laboratory, Department of Chemistry, University of Oxford, 12 Mansfield Road, Oxford, OX1 3TA, UK

*E-mail: luyi.sun@uconn.edu meanwhile it is safe for human cells. Ag NPs and their compounds are widely used in protecting human health and food from bacteria and virus in our daily life. ${ }^{12}$

To maintain the high performance of Ag NPs, it is vital to prevent their agglomeration. Conventional methods to prevent oxidation, agglomeration, or precipitation of Ag NPs typically involve stabilizing agents such as surfactants. ${ }^{13}$ Both ionic surfactants (such as sodium dodecyl sulfate ${ }^{14}$ and cetyltrimethylammonium chloride ${ }^{15}$ ) and non-ionic surfactants (such as Tween 80) ${ }^{16}$ were used to control the particle size of $\mathrm{Ag}$ NPs as well as functioning as a stabilizer. Recently, some novel methods such as chemical reduction by micro-emulsion ${ }^{17}$ and polymer protection ${ }^{18}$ have been developed. Ag NPs with a controllable particle size could be synthesized within the internal space of micelles and micro-emulsions owning to their stabilization effect. ${ }^{19}$ Polymers such as polyvinylpyrrolidine (PVP), ${ }^{20}$ polyethylene glycol, ${ }^{21}$ poly(methyl methacrylate), ${ }^{22}$ poly(vinyl alcohol) ${ }^{23}$ polyaniline, ${ }^{24}$ and polyacrylonitrile $(\mathrm{PAN})^{25}$ were also used to protect the formed $\mathrm{Ag}$ NPs from agglomeration. Recently, inorganic nanosheets ${ }^{26}$ have proved to be effective supports to stabilize metal NPs. ${ }^{27}$ Both positively charged and neutral nanosheets have been used as supports for metal NPs. Layered materials, such as clay minerals (montmorillonite, hectorite, etc.) are suitable for this purpose because they swell instantly in aqueous suspensions which provide a large surface area and large internal space to accommodate $\mathrm{Ag} \mathrm{NPs}{ }^{28}$ Other layered materials ${ }^{29}$ such as graphene was reported to stabilize Ag NPs and the formed composite was used as electrochemical electrode for actuators. ${ }^{30}$

Herein we report the preparation of $\mathrm{Ag}$ NPs supported and stabilized by $\alpha$-zirconium phosphate $\left(\mathrm{Zr}\left(\mathrm{HPO}_{4}\right)_{2} \cdot \mathrm{H}_{2} \mathrm{O}, \alpha-\mathrm{ZrP}\right)$ singlelayer nanosheets. $\alpha-Z r P$ is a versatile layered compound, which has found a wide range of applications. ${ }^{3141}$ The lateral dimensions of $\alpha-\mathrm{ZrP}$ nanosheets can be easily altered by tuning the synthetic conditions. ${ }^{4245}$ It can be easily exfoliated into single-layer nanosheets and used as a support for guest species. ${ }^{46}, 47$ The surface of $\mathrm{ZrP}$ nanosheets is covered 
by a high density of acidic hydroxyl groups. ${ }^{31,42}$ As such, silver cations can be absorbed on the negatively charged $\alpha-\mathrm{ZrP}$ single-layer nanosheet surface by electrostatic interactions and subsequently be reduced to form Ag NPs. The stabilized Ag nanoparticles can potentially act as a catalyst for reduction of 4-nitrophenol. ${ }^{48}$

\section{Experiments}

Silver nitrate $(99.9 \%)$, sodium hydroxide (99\%), and tri-sodium citrate dehydrate (99\%) were purchased from Alfa Aesar. D-Glucose (Dextrose) anhydrous (99\% biotechnology grade) was ordered from Amresco. Tetra- $n$-butylammonium hydroxide solution ( $\mathrm{TBA}^{+} \mathrm{OH}, 1.0 \mathrm{M}$ in methanol) was from Sigma-Aldrich. Zirconyl chloride octahydrate $\left(\mathrm{ZrOCl}_{2} \cdot 8 \mathrm{H}_{2} \mathrm{O}, 98 \%\right.$ ) was purchased from Sigma-Aldrich. O-Phosphoric acid was purchased from Fisher Scientific. Ammonium hydroxide (28\%) was purchased from Sigma-Aldrich. All chemicals were used as received without further purifications.

\subsection{Synthesis and exfoliation of $\alpha-\mathrm{ZrP}$}

$\alpha-\mathrm{ZrP}$ was prepared via a hydrothermal method. ${ }^{49}$ Typically, $6.0 \mathrm{~g}$ $\mathrm{ZrOCl}_{2} 8 \mathrm{H}_{2} \mathrm{O}$ was mixed with $60.0 \mathrm{~mL} 6.0 \mathrm{M} \mathrm{H}_{3} \mathrm{PO}_{4}$ and the mixture was reacted in a Teflon-lined pressure vessel at $200{ }^{\circ} \mathrm{C}$ for $24 \mathrm{~h}$. After the reaction, the product was centrifuged and washed three times with water and ethanol. After washing, the obtained $\alpha-\mathrm{ZrP}$ was dried at $100{ }^{\circ} \mathrm{C}$ for $24 \mathrm{~h}$. The dried $\alpha-\mathrm{ZrP}$ was then ground into fine powders.

The prepared $\alpha-\mathrm{ZrP}$ was then exfoliated by $\mathrm{TBA}^{+} \mathrm{OH}^{-}$in an aqueous dispersion maintained at $0{ }^{\circ} \mathrm{C}$ in an ice bath. ${ }^{50}$ Typically, $0.10 \mathrm{~g}$ $\alpha-\mathrm{ZrP}$ was dispersed in $10.0 \mathrm{~mL}$ water and ultrasonicated for one hour in an ice bath. Then, one molar equivalent $\mathrm{TBA}^{+} \mathrm{OH}^{-}$was added into $\alpha$ $\mathrm{ZrP}$ water dispersion. The mixture was stir for one hour and subsequently ultrasonicated for an hour in an ice bath to exfoliate $\alpha-\mathrm{ZrP}$.

\subsection{Synthesis of silver nanoparticles}

Generally, a silver precursor was first mixed with $\alpha$-ZrP single-layer nanosheets at a predetermined molar ratio before the reducing agent was introduced. According to different methods, heating or cooling was applied during the reduction process.

\subsubsection{Reduction of Ag NPs by glucose}

The traditional silver mirror reaction is adopted in the glucose reduction method. ${ }^{51}$ Ammonium hydroxide (28.0 wt. \%) was added drop by drop into $50.0 \mathrm{~mL}, 0.10 \mathrm{M}$ silver nitrate solution under stirring at $60{ }^{\circ} \mathrm{C}$ to make Tollens' reagent $\left(\left[\mathrm{Ag}\left(\mathrm{NH}_{3}\right)_{2}\right]^{+}\right)$stock solution. During reaction, a brown precipitate first formed. Ammonium hydroxide was continuously added and gradually the solution became clear. Then, a few drops of sodium hydroxide solution were added into the solution. If the brown precipitate reformed, additional ammonia solution was added drop by drop until the precipitate was dissolved. Then, a suspension containing the prepared $\alpha$-ZrP single-layer nanosheets was added to mix with the Tollens' reagent at a pre-determined molar ratio (Ag: $\alpha-\mathrm{ZrP}$ ratio). Finally, glucose (two molar equivalent of silver) was added into the mixture to reduce $\mathrm{Ag}^{+}$. Three sets of experiments with $\mathrm{Ag}^{+}$to $\alpha-\mathrm{ZrP}$ molar ratio of $0.5: 1,1.0: 1$, and 2.0:1 were conducted to study the stabilizing effect.

\subsubsection{Reduction of silver $\mathrm{NPs}$ by $\mathrm{NaBH}_{4}$}

Three solutions, one containing $0.20 \mathrm{~g}$ silver nitrate and $50.0 \mathrm{~mL}$ water, the second was a $13.0 \mathrm{~mL}$ suspension of $\alpha-\mathrm{ZrP}$ single-layer nanosheets $(0.01367 \mathrm{~g} / \mathrm{mL})$, and the third containing $0.060 \mathrm{~g} \mathrm{NaBH}_{4}$ and $15.0 \mathrm{~mL}$ water, were all cooled down to $0{ }^{\circ} \mathrm{C}$ in an ice bath. The first two were mixed in an ice bath under stirring. Subsequently, the reducing agent $\left(\mathrm{NaBH}_{4}\right)$ was added into the mixture at $0{ }^{\circ} \mathrm{C}$ and stirred for 2 hours until no apparent color change.

\subsubsection{Reduction of silver NPs by tri-sodium citrate}

A solution of $50.0 \mathrm{~mL} \mathrm{AgNO}_{3}\left(10^{-3} \mathrm{M}\right)$ was heated to $105{ }^{\circ} \mathrm{C}$. Then, $0.60 \mathrm{~mL}$ suspension of $\alpha-\mathrm{ZrP}$ single-layer nanosheets $(0.01367 \mathrm{~g} / \mathrm{mL})$ was added to the $\mathrm{AgNO}_{3}$ solution under stirring. To this mixture, $5.0 \mathrm{~mL}$ of $1 \%$ tri-sodium citrate was added drop by drop. The reaction was carried out until no further color change after the solution is turned to orange. Then, the mixture was removed from the hot plate and further stirred overnight.

\subsection{Characterizations}

The products were characterized by a X-ray diffractometer (Bruker D8 with $\mathrm{Cu} \mathrm{K} \alpha$ radiation, $\lambda=1.5406 \AA, 40 \mathrm{kV}, 40 \mathrm{~mA}$ ) and a transmission electron microscope (JEOL JEM-2010 FASTEM operated at $200 \mathrm{kV}$ ).

\section{Results and Discussion}

$\alpha-Z r P$ can be effectively exfoliated into single-layer nanosheets by $\mathrm{TBA}^{+} \mathrm{OH}^{-50}$ During the exfoliation process, $\mathrm{TBA}^{+}$was first intercalated in between $\alpha$-ZrP layers through ion exchange. ${ }^{50}$ The interlayer distance was expanded by the large $\mathrm{TBA}^{+}$ions thus weakening the interlayer interactions. Upon further mechanical shearing (stirring and sonication), the intercalated $\alpha-\mathrm{ZrP}$ can be exfoliated into single layers and stably dispersed to form a suspension. The exfoliation process is illustrated in Fig. 1. Before exfoliation, the as-prepared $\alpha-\mathrm{ZrP}$ (Fig. 2A) has a typical size of ca. $600-800 \mathrm{~nm}$ in diameter. After exfoliation, the $\alpha-\mathrm{ZrP}$ singlelayer nanosheets were ruptured into thin fragments (Fig. 1B). The large surface area of $\alpha-\mathrm{ZrP}$ single-layer nanosheets makes them an ideal candidate to support and disperse Ag NPs.

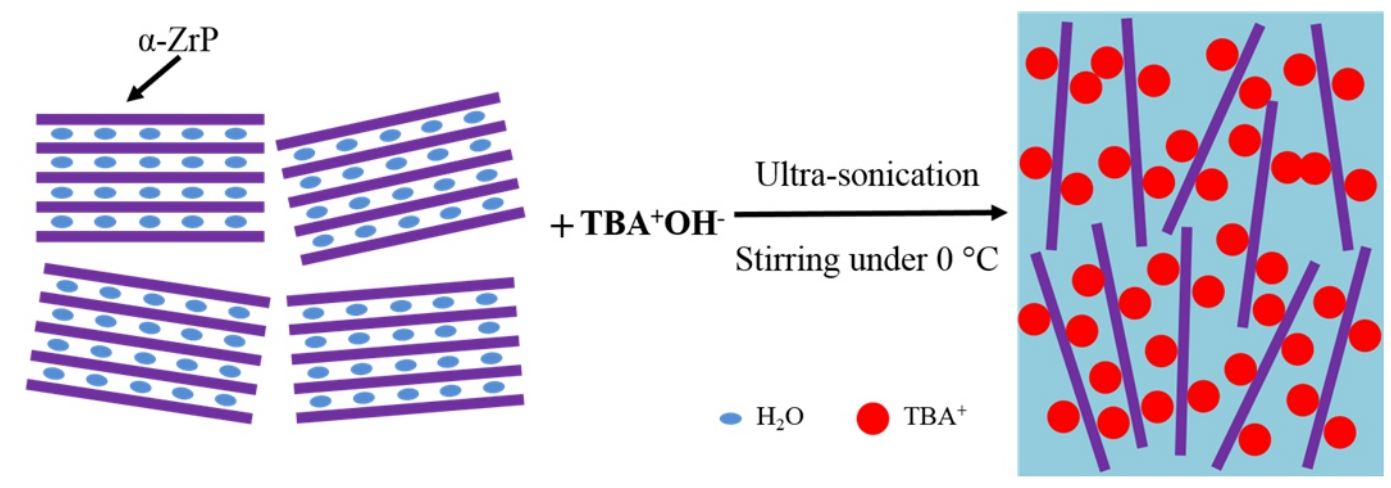

Fig. 1 Schematic of $\alpha-\mathrm{ZrP}$ exfoliation by $\mathrm{TBA}^{+} \mathrm{OH}^{-}$. 
The negatively charged $\alpha$-ZrP single-layer nanosheets can effectively attract positively charged silver cations by electrostatics interactions. When they are mixed together, the attached silver cations can be reduced and stabilized on the nanosheet support. The overall process is illustrated in Fig. 3. Three conventional reduction agents, including glucose, $\mathrm{NaBH}_{4}$, and sodium tri-citrate, were adopted to study the reduction process.

Three Ag NP samples were prepared when silver nitrate to $\alpha-\mathrm{ZrP}$ single-layer nanosheets molar ratio was varied from $0.5: 1$ to $2.0: 1$ in an excessive amount of glucose. The samples were prepared by varying the amounts of silver nitrate solution $(2.5,5.0$, and $10.0 \mathrm{~mL}, 0.10 \mathrm{M})$ while maintaining the amount of $\alpha-\mathrm{ZrP}(0.01367 \mathrm{~g} / \mathrm{mL}, 10.0 \mathrm{~mL})$. As shown in Fig. 4, the $\mathrm{Ag}$ NPs were well dispersed and supported on $\alpha-\mathrm{ZrP}$ single-layer nanosheets with an average diameter of $13.9 \pm 3.5 \mathrm{~nm}$ (Fig. 4A), $17.3 \pm 5.4 \mathrm{~nm}$ (Fig. 4B), and $18.3 \pm 4.4 \mathrm{~nm}$ (Fig. 4C) at 0.5:1, 1.0:1, and 2.0:1 silver nitrate to $\alpha-\mathrm{ZrP}$ single-layer nanosheets molar ratios, respectively. The particle size stabilized at ca. $18 \mathrm{~nm}$ when the $\mathrm{Ag}^{+}$to $\alpha-\mathrm{ZrP}$ molar ratio reached 2:1. Overall, the results suggested that the dispersion of the reduced Ag NPs on $\alpha-\mathrm{ZrP}$ single-layer nanosheet support was irrelevant to the starting molar ratio of silver to $\alpha-\mathrm{ZrP}$ (Fig. 4). This is probably because the size of the synthesized Ag NPs was much smaller compared to lateral dimensions of the $\alpha$-ZrP single-layer nanosheets (Fig. 2B).

Since Ag NP size stabilized when silver nitrate to $\alpha$-ZrP single-

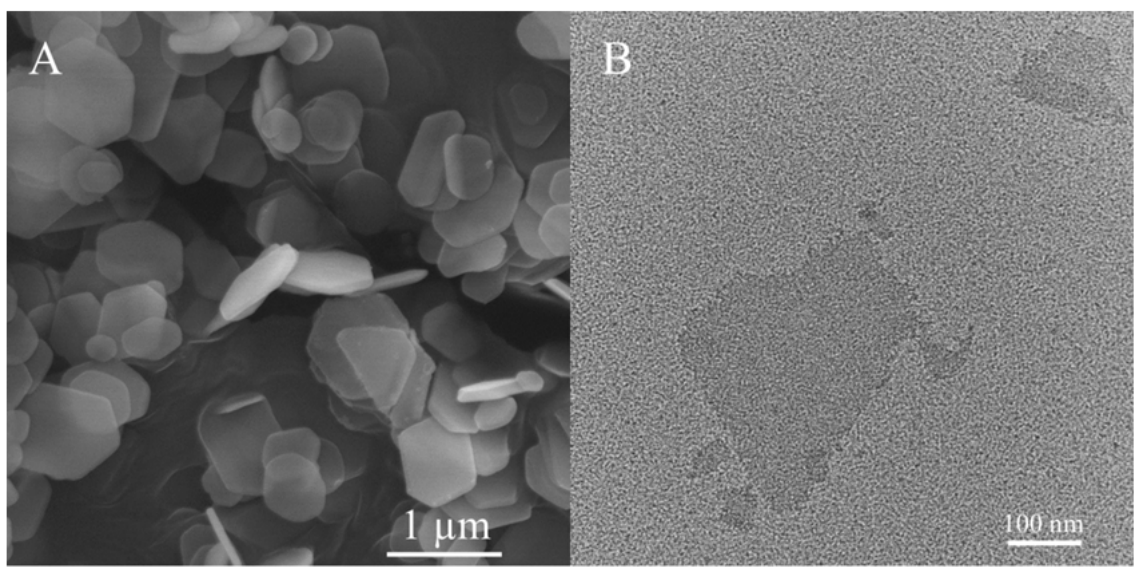

Fig. 2 (A) SEM image of the as-prepared $\alpha-Z r P$ and (B) TEM image of the prepared $\alpha-Z r P$ single-layer nanosheets.

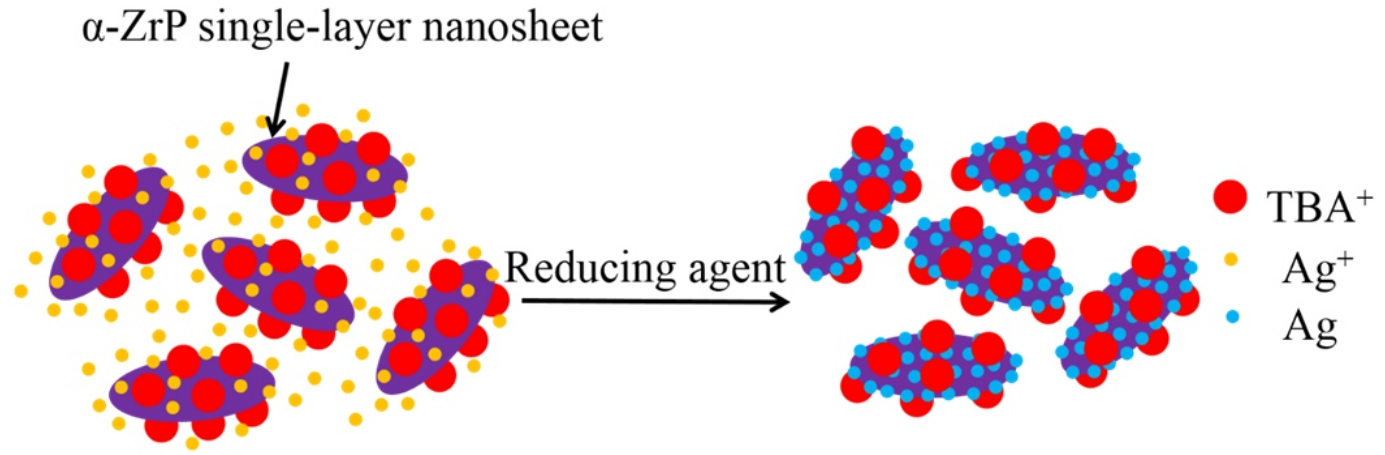

Fig. 3 Schematic of silver cations stabilized and reduced on $\alpha-Z r P$ single-layer nanosheets.

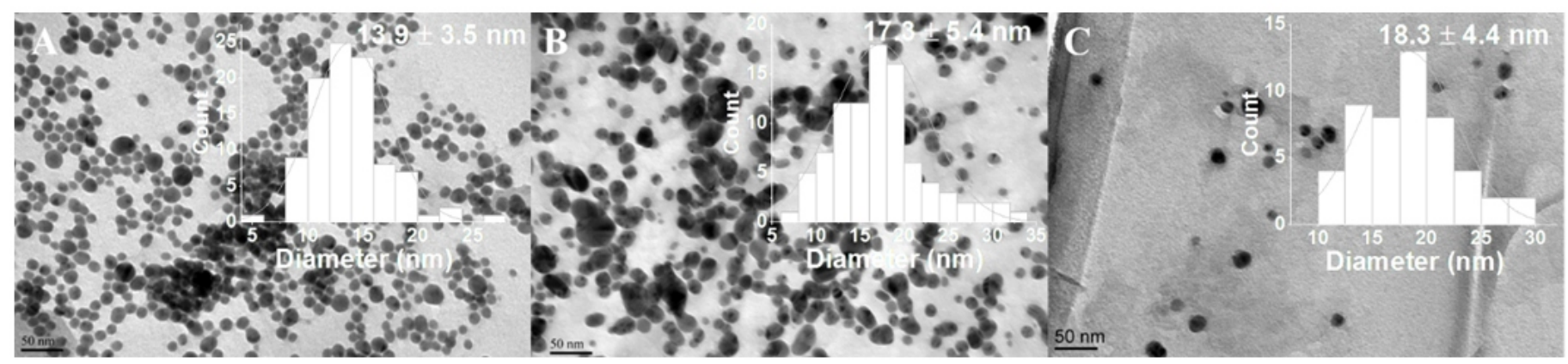

Fig. 4 TEM images of the Ag NPs reduced by glucose at $\mathrm{Ag}^{+}$to $\alpha-\mathrm{ZrP}$ molar ratio of 0.5:1 (A), 1.0:1 (B) and 2.0:1 (C). 


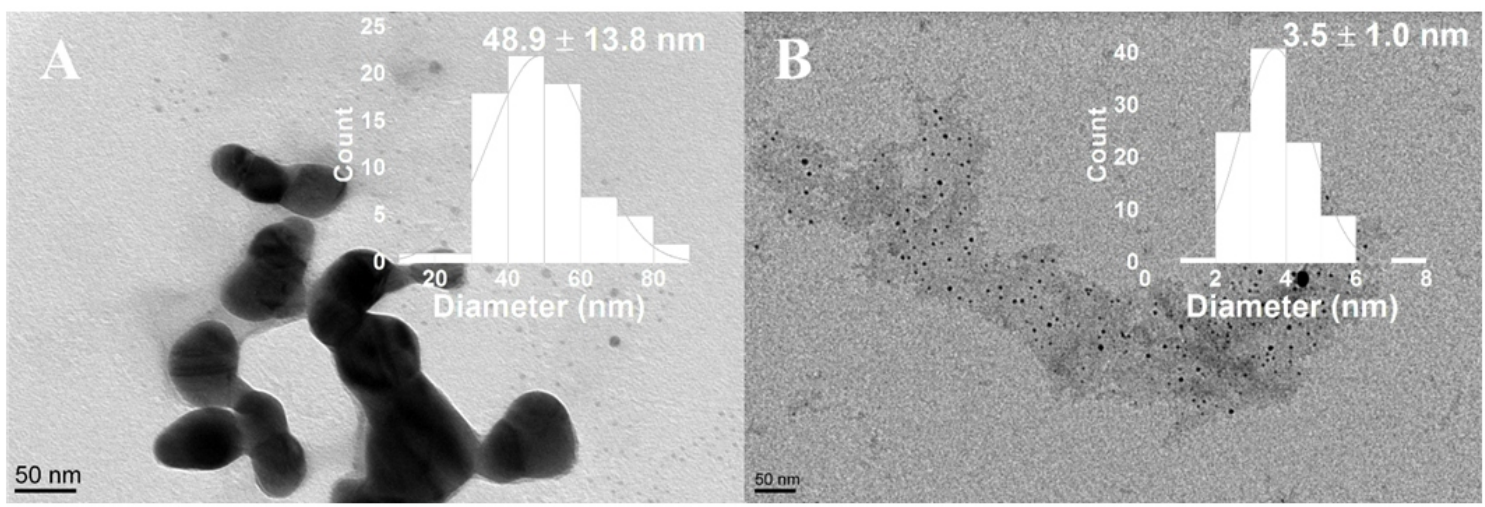

Fig. 5 TEM images of Ag NPs reduced by $\mathrm{NaBH}_{4}$ (A) and tri-sodium citrate (B) at a silver to $\alpha$-ZrP molar ratio of 2.0:1.

layer nanosheets molar ratio reached 2.0:1, two other reducing agents, $\mathrm{NaBH}_{4}$ and tri-sodium citrate, were used to reduce silver at this molar ratio. $\mathrm{NaBH}_{4}$ is a powerful reducing agent, which is commonly used to synthesize metal NPs. ${ }^{52}$ Previous studies indicated that $\mathrm{NaBH}_{4}$ also acted as a stabilizer when used to reduce $\mathrm{Ag}^{+}$to prepare NPs. ${ }^{53}$ The other reducing agent tri-sodium citrate is often used in the Turkevich process ${ }^{54}$ where citrate ions simultaneously act as a reducing agent as well as a stabilizer. ${ }^{55}$ Thus, in addition to $\alpha$-ZrP single-layer nanosheets, $\mathrm{NaBH}_{4}$ and citrate ions can further stabilize the formed Ag NPs, protecting them from aggregation. Fig. $5 \mathrm{~A}$ and $\mathrm{B}$ show the Ag NPs reduced by $\mathrm{NaBH}_{4}$ and tri-sodium citrate with an average particle size of $48.9 \pm 13.8 \mathrm{~nm}$ and $3.5 \pm 1.0 \mathrm{~nm}$, respectively. The tri-sodium citrate reduced Ag NPs was distinctively smaller than those reduced by $\mathrm{NaBH}_{4}$ and glucose, probably because citrate is a much milder reducing agent. ${ }^{56}$

\section{Conclusion}

In this paper, a new support, $\alpha$-ZrP single-layer nanosheets were adopted to stabilize the synthesized Ag NPs. Three different reducing agents: glucose, $\mathrm{NaBH}_{4}$, and tri-sodium citrate were used to reduce $\mathrm{Ag}^{+}$ cations to synthesize Ag NPs. The TEM characterization showed that the synthesized Ag NPs were well dispersed and supported on the $\alpha-\mathrm{ZrP}$ single-layer nanosheets with an average diameter ranging from $18.3 \pm$ $4.4 \mathrm{~nm}$ (glucose), $48.9 \pm 13.8 \mathrm{~nm}\left(\mathrm{NaBH}_{4}\right)$, to $3.5 \pm 1.0 \mathrm{~nm}$ (tri-sodium citrate). Overall, the results showed that $\alpha$-ZrP single-layer nanosheets are an effective support to stabilize the synthesized Ag NPs and prevent particle agglomeration.

\section{Acknowledgment}

We gratefully acknowledge the financial support from the ACS Petroleum Research Fund (Grant No. 57580-ND5) and the National Science Foundation (CMMI-1562907).

\section{References}

1. P. Mulvaney, (2002). In Nanoscale Materials in Chemistry, K. J. Klabunde (Ed.), pp 121-167.

2. Y. Son, J. Yeo, H. Moon, T. W. Lim, S. Hong, K. H. Nam, S. Yoo, C. P. Grigoropoulos, D. Y. Yang and S. H., Ko, Adv.Mater, 2011, 23 (28), 31763181.

3. R. C. Hayward, D. A. Saville and I. A. Aksay, , Nature, 2000, 404 (6773), 5659.

4. A. Kleibert, W. Rosellen, M. Getzlaff and J. Bansmann, Beilstein J.Nanotech., 2011, 2, 47-56.

5. L. N. Lewis, Chem. Rev., 1993, 93 (8), 2693-2730.
6. U. Kreibig, M. V., Springer Series in Materials Science 25 1995, New York, Springer-Verlag, 24.

7. Y. A. Krutyakov, A. A. Olenin and G. V. Lisichkin, Russ. Chem. Rev. 2008, 77, 233.

8. M. Kowalska, H. Güler and D. L. Cocke, Sci. Total Environ.,1994, 141 (1-3), 223-240.

9. S. Silver, L. Phung and G. Silver, J. Ind. Microbiol. Biotechnol., 2006, 33 (7), 627-634.

10. M. Rai, A. Yadav and A. J. B. A. Gade, Biotechnol Adv., 2009, 27 (1), 7683.

11. S. Galdiero, A. Falanga, M. Vitiello, M. Cantisani, V. Marra and M. J. M. Galdiero, Molecules, 2011, 16 (10), 8894-8918.

12. K. I. Batarseh, J. Antimicrob. Chemother, 2004, 54 (2), 546.

13. M. Paule Pileni, New J. Chem., 1998, 22 (7), 693-702.

14. D. K. Bhui, H. Bar, P. Sarkar, G. P. Sahoo, S. P. De and A. Misra, J. Mol. Liq. 2009, 145 (1), 33-37.

15. M. P. J. N. M. Pileni, Nat. Mater,,2003, 2 (3), 145.

16. J. Soukupová, L. Kvítek, A. Panáček, T. Nevěčnáand R. Zbořil, Mater. Chem.Phys., 2008, 111 (1), 77-81.

17. I. Lisiecki and M. P. Pileni, J. Am. Chem. Soc., 1993, 115 (10), 3887-3896.

18. N. Yanagihara and Y. Tanaka, H. Okamoto, Chem. Lett., 2001, 30 (8), 796797.

19. Y. M. Tricot and J. H. Fendler, J. Am. Chem. Soc., 1984, 106 (24), 73597366.

20. M. Zheng, M. Gu, Y. Jin and G. Jin, Mater. Res.Bull.,2001, 36 (5-6), $853-$ 859.

21. C. Luo, Y. Zhang, X. Zeng, Y. Zeng and Y. Wang, J. Colloid Interf. Sci., 2005, 288 (2), 444-448.

22. N. Singh and P. K. Khanna, Mater. Chem.Phys.,2007, 104 (2-3), 367-372.

23. Y. Zhou, S. H. Yu, C. Y. Wang, X. G. Li, Y. R. Zhu and Z. Y. Chen, , $A d v$. Mater., 1999, 11 (10), 850-852.

24. P. K. Khanna, N. Singh, S. Charan and A. K. Viswanath, Mater. Chem. Phys., 2005, 92 (1), 214-219.

25. Z. Zhang, L. Zhang, S. Wang, W. Chen and Y. Lei, , Polymer, 2001, 42 (19), 8315-8318

26. J. Yu, Q. Wang, D. O'Hare and L. Sun, Chem. Soc. Rev. 2017, 46 (19), 59505974.

27. L. T. Zhuravlev, Langmuir, 1987, 3 (3), 316-318.

28. N. A. Kotov, I. Dekany and J. H. Fendler, J. Phys.Chem.,1995, 99 (35), 13065-13069.

29. J. Yu, B. R. Martin, A. Clearfield, Z. Luo and L. Sun, Nanoscale, 2015, 7 (21), 9448-9451.

30. L. Lu, J. Liu, Y. Hu, Y. Zhang and W. Chen, Adv. Mater, 2012, 1270-1274.

31. Y. Zhou, R. Huang, F. Ding, A. D. Brittain, J. Liu, M. Zhang, M. Xiao, Y. Meng and L. Sun, ACS Appl. Mater. Inter, 2014, 6 (10), 7417-7425.

32. W. J. Boo, L. Sun, J. Liu, A. Clearfield and H. J. Sue, J. Phys. Chem. C, 2007, 111 (28), 10377-10381.

33. W. J. Boo, L. Y. Sun, J. Liu, A. Clearfield, H. J. Sue, M. J. Mullins and H. 
Pham, Compos. Sci. Technol., 2007, 67 (2), 262-269.

34. E. Moghbelli, L. Sun, H. Jiang, W. J. Boo and H. Sue, Polym. Eng. Sci.,2009, 49 (3), 483-490.

35. L.Sun, J. Liu, S. R. Kirumakki, E. D. Schwerdtfeger, R. J. Howell, K. Albahily, S. A. Miller, A. Clearfield and H. Sue, Chem. Mat., 2009, 21 (6), 1154-1161.

36. Q. Wang, J. Yu, J. Liu, Z. Guo, A. Umar and L. Sun, Sci. Adv. Mater., 2013, 5, 469-474.

37. H. Hu, J. C. Martin, M. Zhang, C. S. Southworth, M. Xiao, Y. Meng and L. Sun, , RSC Adv., 2012, 2 (9), 3810-3815.

38. L. Sun and H. J. Sue, Nova Science Publishers: New York, USA, 2010

39. L. Y. Sun, W. J. Boo, D. H. Sun, A. Clearfield and H. J. Sue, , Chem. Mat. 2007, 19 (7), 1749-1754.

40. Y. Zhou, J. Liu, M. Xiao, Y. Meng and L. Sun, ACS Appl. Mater. Interfaces. 2016, 8 (8), 5547-5555.

41. H. Hu, J. C. Martin, M. Xiao, C. S. Southworth, Y. Meng and L. Sun, J. Phys. Chem.C, 2011, 115 (13), 5509-5514.

42. L. Y. Sun, W. J. Boo, R. L. Browning, H. J. Sue and A. Clearfield, , Chem. Mat. 2005, 17 (23), 5606-5609.

43. L. Sun, W. J. Boo, J. Liu, A. Clearfield, H. J. Sue, N. Verghese, H. Q. Pham and J. Bicerano, Macromol. Mater. Eng. 2009, 294, 103-113.

44. L. Sun, J. Y. Oreilly, D. Kong, J. Y. Su, W. J. Boo, H. Sue and A. Clearfield, J. Colloid Interf. Sci., 2009, 333 (2), 503-509.

45. J. Yu, L. Xiang, B. R. Martin, A. Clearfield and L. Sun, Chem. Commun.,
2015, 51 (57), 11398-11400.

46. Y. Zhou, I. Noshadi, H. Ding, J. Liu, R. Parnas, A. Clearfield, M. Xiao, Y. Meng and L. Sun, Catalysts, 2018, 8 (1), 17.

47. Y. Zhou,; A.Wang, Z. Wang, M. Chen, W. Wang, L. Sun and X. Liu, RSC $A d v ., 2015,5$ (114), 93969-93978.

48. Y. Li,; J. Y. Lan, J. Liu,; J. Yu, Z. Luo, W. Wang and L. Sun, Ind. Eng. Chem. Res., 2015, 54 (21), 5656-5663.

49. L. Sun, W. J. Boo, H. J. Sue and A. Clearfield, New J. Chem., 2007, 31 (1), 39-43.

50. L. Sun, W. J. Boo, D. Sun, A. Clearfield and H. J. Sue, Chem. Mater, 2007 , 19 (7), 1749-1754.

51. M. Montazer,; F. Alimohammadi, A. Shamei and M. K. Rahimi, I Carbohydr Polym., 2012, 87 (2), 1706-1712.

52. X. Dong, X. Ji, J. Jing, M. Li, J. Li and W. Yang, J. Phys. Chem. C, 2010, 114 (5), 2070-2074.

53. A. Zielińska, E. Skwarek, A. Zaleska, M. Gazda and J. Hupka, Proced. Chem., 2009, 1 (2), 1560-1566.

54. J. Turkevich, P. C. Stevenson and J. Hillier, Discuss. Faraday Soc., 1951, 11 (0), 55-75.

55. A. Henglein and M. Giersig, J. Phys. Chem. B, 1999, 103 (44), 9533-9539.

56. K. R. Brown, D. G. Walter and M. J. Natan, Chem. Mater, 2000, 12 (2), 306-313.

Publisher's Note Engineered Science Publisher remains neutral with regard to jurisdictional claims in published maps and institutional affiliations. 